\title{
PENGENDALIAN PERSEDIAAN BAHAN BAKU GULA MENGGUNAKAN METODE EOQ DAN JUST IN TIME
}

\author{
Vito Arifanto Pradana ${ }^{1}$, Ribangun Bamban Jakaria ${ }^{2}$ \\ Program Studi Teknik Industri, Fakultas Sains dan Teknologi, Universitas Muhammadiyah Sidoarjo ${ }^{12}$ \\ email $^{1}$ : vitoarfianto@umsida.ac.id, email² : ribangunbz@umsida.ac.id
}

\begin{abstract}
Abstrak
Pengendalian Persediaan Bahan Baku Gula Menggunakan Metode EOQ Dan Just In Time. Penelitian ini dilakukan pada PT. Singa Mas Indonesia dengan permasalahan persediaan bahan baku gula yang tidak stabil serta kurang efisien dari segi biaya, kuantitas, dan waktu pemesanan, penelitian ini bertujuan untuk menstabilkan stok bahan baku gula serta efisien dari segi biaya, kuantitas dan waktu pemesanan. Penelitian ini menggunakan metode Economy Order Quantity (EOQ) karena metode tersebut merupakan sebuah teknik kontrol persediaan yang meminimalkan biaya total dari pemesanan dan penyimpanan bahan baku. Penelitian ini juga menggunakan metode Just In Time (JIT) ksrena disebut sebagai sistem pengendalian persediaan dan produksi yang menghendaki bahan baku dibeli, dan unit yang diproduksi hanya sebatas kebutuhan produksi. Sehingga sesuai bagi perusahaan yang terbatas gudang bahan bakunya atau perusahaan yang ingin meniadakan biaya penyimpanan bahan baku. Hasil EOQ pengendalian persediaan gula 2016/2017 didapatkan kuantitas sebesar $70.451 \mathrm{Kg}$, frekuensi 5 kali, biaya total persediaan sebesar Rp 11.679.041. sedangkan pada metode JIT 2016/2017 didapatkan kuantitas sebesar $3.896 \mathrm{Kg}$, frekuensi sebanyak 96 kali, total biaya JIT sebesar Rp. 2.244.898.
\end{abstract}

Kata kunci: pengendalian, persediaan,bahan baku, Just In Time, EOQ

\section{Abstract}

Sugar Raw Material Inventory Control Using The EOQ and JIT Methods.This research was conducted at PT. Singa Mas Indonesia with the problem of the supply of sugar raw materials that are unstable and less efficient in terms of cost and time of ordering, with this the authors use the EOQ and JIT methods with the aim of stabilizing the sugar raw material stock and efficiently in terms of cost and time of ordering. The Economy Order Quantity (EOQ) is an inventory control technique that minimizes the total cost of ordering and storing raw materials. Whereas Just In Time (JIT) can be referred to as an inventory and production control system that requires raw materials to be purchased, and units produced are only limited to production needs so that it is suitable for companies limited to raw material warehouses or companies that want to eliminate raw material storage costs. The research was conducted in the hope of minimizing the total cost of sugar raw material inventories and in terms of ordering time efficiency. The results of the 2016/2017 sugar inventory control EOQ obtained a quantity of

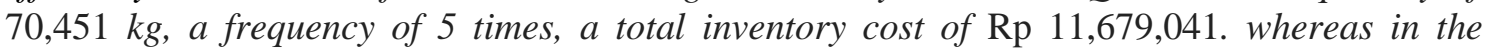
2016/2017 JIT method a quantity of 3,896 kg was obtained, a frequency of 96 times, the total cost of the JIT was Rp. 2,244,898.

Keywords: control, inventory, raw materials, Just In Time, EOQ

\section{PENDAHULUAN}

Setiap perusahaan, didirikan untuk mencapai berbagai macam tujuan, salah satunya yaitu memperoleh laba atau keuntungan dan menjaga kelancaran proses produksi. Untuk mencapai tujuan tersebut tidaklah mudah, karena dipengaruhi oleh berbagai faktor. Salah satu faktor penting yang mempengaruhi pencapaian tujuan, khususnya pada perusahaan manufaktur adalah kelancaran proses produksi. Kelancaran proses produksi itu sendiri dipengaruhi oleh berbagai faktor. Salah satunya yang penting adalah faktor pengadaan dan pengendalian persediaan bahan baku yang akan diolah dalam proses produksi. Faktor produksi ini sering disebut sebagai persediaan bahan baku (Maharani ,2015).

Permasalahan yang ada pada perusahaan PT. Singa Mas Indonesia adalah kurang optimalnya sistem pengendalian persediaan bahan baku gula, kurang optimalnya jumlah kuantitas pemesanan 
bahan baku gula dikarenakan keterbatasan kapasitas penyimpanan bahan baku, banyaknya frekuensi pemesanan yang mennyebabkan besarnya biaya total persediaan bahan baku gula pada PT. Singa Mas Indonesia. Menurut data perusahaan, pada tahun 2016 kebutuhan bahan baku per tahun $374.000 \mathrm{~kg}$, kuantitas pemesanan optimal $18.700 \mathrm{~kg}$ per pemesanan, dengan frekuensi pemesanan sebanyak 20 kali, dengan biaya total persediaan sebesar Rp. 84.000.000. Kebijakan perusahaan terkait permasalahan pengendalian persediaan bahan baku yang kurang optimal mengakibatkan tidak maksimalnya keuntungan perusahaan dan tidak efisien dari segi biaya maupun waktu dan bahkan dapat mengakibatkan kerugian perusahaan. Dari hal tersebut penelitian ini diharapkan dapat meminimalkan biaya persediaan bahan baku dan juga mengendalikan persediaan dari segi kuantitas serta efisiensi waktu pembelian bahan baku untuk memaksimalkan kegiatan produksi.

\section{TINJAUAN PUSTAKA}

\section{Persediaan}

Persediaan adalah suatu bahan atau barang yang disimpan berupa barang baku atau barang jadi yang akan digunakan untuk memenuhi tujuan tertentu, misalnya untuk digunakan dalam proses produksi atau perakitan, untuk dipasarkan atau dijual kembali (Ahyadi, 2017).

\section{Pengelolaan Persediaan}

Pengelolaan persediaan merupakan kegiatan manajemen persediaan yang saling bertautan satu dengan yang lainnya dengan perencanaan yang baik dalam waktu, jumlah, kualitas, maupun biayannya (Sari, 2010).

Menurut (Soebandi, 2014), persediaan selalu dbutuhkan untuk kegiatan produksi, baik perusahaan besar dan kecil maupun UKM. Berikut ini adalah beberrapa fungsi dari persediaan:

a. Persediaan diperlukan sebagai cadangan stok perusahaan baik berupa bahan mentah maupun bahan setengah jadi untuk mengantisipasi keterlambatan pemesanan.

b. Untuk mengantisipasi kenaikan permintaan konsumen.

c. Untuk memanfaatkan potongan harga dari pemasok, biasanya pemasok memberikan potongan harga untuk jumlah tertentu, dikarenakan pemasok tersebut kelebihan persediaan. Merupakan keuntungan perusahaan untuk mendapatkan barang dengan harga murah.

d. Mengantisipasi kenaikan harga , maka perusahaan perlu menyediakan bahan baku lebih demi menghindari kenaikan harga bahan baku.

Biaya yang selalu timbul dalam persediaan anatara lain; holding cost, set up cost, ordering cost, biaya-biaya tersebut adalah biaya pokok yang berarti biaya yang tidak dapat dihindari, tetapi dapat diminimalkan dan diperhitungkan tingkat efisiensinya didalam menentukan kebijakan manajemen persediaan. Berikut ini merupakan definisi biaya persediaan:

$>$ Biaya penyimpanan (holding cost/caryying cost)

Merupakan salah satu biaya yang timbul didalam manajemen persediaan, dalam usaha mengondisikan persediaan agar terhindarkan dari kerusakan, keusangan atau keausan, dan kehilangan. Dengan demikian biaya penyimpanan dapat diuraikan lagi sebagai berikut:

a. Biaya fasilitas penyimpanan (penerangan, pendingin, pemanas)

b. Biaya Modal (Opportunity Cost of Capital)

c. Biaya keusangan dan keausan (Amortisation)

d. Biaya Asuransi Persediaan

e. Biaya perhitungan fisik dan konsolidasi laporan.

f. Biaya kehilangan barang

g. Biaya penanganan persediaan (Handling Cost)

Biaya pemesanan (Order Cost/Procurement Cost)

Biaya-biaya yang muncul selama proses pemesanan sampai barang tersebut dalam tahap logistik dari pemasok antara lain:

a. Biaya ekspedisi

b. Biaya upah

c. Biaya telepon

d. Biaya surat menyurat

e. Biaya pemeriksaan penerimaan (raw material inspection)

$>$ Biaya persiapan (set up cost)

Merupakan biaya-biaya yang timbul dalam menyiapkan mesin dan peralatan untuk dipergunakan dalam proses konversi antara lain sebagai berikut:

a. Biaya Mesin yang Menganggur

b. Biaya Penyiapan Tenaga Kerja

c. Biaya Scheduling

d. Biaya Ekspedisi

$>$ Biaya Kehabisan Stok

Biaya yang timbul akibat kehabisan persediaan yang disebabkan kesalahan perhitungan dll

a. Biaya Kehilangan Penjualan

b. Biaya Kehilangan Pelanggan

c. Biaya Pemesanan Khusus

d. Biaya Ekspedisi

e. Selisih Harga

f. Terganggunya Operasi Produksi

g. Tambahan Pengeluaran Kegiatan Manajerial 
biaya-biaya tersebut adalah biaya pokok yang berarti biaya yang tidak dapat dihindari, tetapi dapat diminimalkan dan diperhitungkan tingkat efisiensinya didalam menentukan kebijakan manajemen persediaan (Tampubolon, 2004).

\section{EOQ}

Economic Order Quantity (EOQ) adalah jumlah pembelian persediaan yang dilakukan dengan efisien agar biaya persediaan keseluruhan menjadi sekecil mungkin. EOQ dihitung dengan memperhatikan variabel biaya persediaan. Ada 2 macam biaya yang digunakan sebagai dasar perhitungan EOQ, yaitu biaya pemesanan (ordering cost) dan biaya penyimpanan (carrying cost) (Turnip, 2017).

\section{Just In Time}

JIT merupakan sistem produksi yang komperehensif dan sistem manajemen persediaan dimana bahan baku dibeli dan diproduksi sebanyak yang dibutuhkan serta digunakan pada saat yang tepat dalam setiap proses produksi (Simanjuntak, 2017).

\section{Konsep JIT}

Berikut ini adalah konsep (JIT) yang bertujuan mengefisienkan waktu serta meminimalkan biaya yang berhubungan dengan pembelian dan produksi :

a. Mengurangi jumlah pemasok

b. Mengurangi atau mengeliminasi waktu dan biaya negosiasi dengan pemasok

c. Memiliki konsumen dengan program pembelian yang mapan

d. Mengeliminasi atau mengurangi aktivitas dan nilai yang tidak pernah bertambah

e. Mengurangi waktu dan biaya untuk program pemeriksaan mutu

f. Mengurangi atau meniadakan barang dalam proses

g. Mengurangi atau meniadakan leadtime

h. Mengurangi atau meniadakan setup

i. Menyederhanakan pengolahan produk.

Dengan menerapkan konsep-konsep just in time tersebut perusahaan dapat mengendalikan dua tujuan strategis yaitu waktu produksi tepat waktu dan mengendalikan biaya (untuk memenangkan persaingan harga pasar) (Simanjuntak, 2017)

\section{METODOLOGI PENELITIAN}

Penelitian dilakukan di PT. Singa Mas Indonesia yang terletak di Pandaan, Jawa Timur, dan dilakukan selama empat bulan. Mulai dari bulan November sampai dengan bulan Februari 2019.

Survey pendahuluan dilakukan dengan merencanakan kegiatan penelitian sesuai dengan lokasi dan waktu yang ditentukan serta bertujuan untuk dapat menentukan perumusan permasalahan pada perusahaan, survey pendahuluan berupa:

1. Studi pustaka merupakan sumber referensi penulis sebagai acuan dan didapat dari buku dan jurnal, bertujuan sebagai pembanding sumber literasi, Buku Teknik Industri Manajemen Operasional, Buku Pengantar Teknik Industri, dan Jurnal analisis persediaan bahan baku menggunakan metode EOQ dan JIT, metode tersebut menjadi usulan sistem pengendalian persediaan bagi perusahaan.

2. Studi lapangan dilakukan dengan melakuakan observasi langsung ke PT Singa Mas Indonesia yang ada di Pandaan, Jawatimur. Untuk mengetahui secara rill kondisi persediaan bahan baku didalamnya. Untuk mendapatkan data berupa informasi mengenai permasalahan yang actual yang terjadi pada saat kegiatan proses produksi berlangsung.

Perumusan masalah didapatkan dari hasil studi pada perusahaan PT. Singa Mas Indonesia yaitu masalah pengendalian persediaan bahan baku gula dengan penyelesaian masalah berdasarkan hasil studi pustaka menggunakan metode EOQ dan Just In Time.

Pada proses penelitian yang dilakukan ini terdapat metode yang kami kumpulkan yaitu dengan menggunakan jenis penelitian data primer dan data data sekunder.

Pengolahan data dilakukan dengan menggunakan metode Economic Order Quantity dan Just In Time guna menghitung biaya persediaan bahan baku dan efisiensi waktu dalam perusahaan tersebut.

1. Pengumpulan data primer \& sekunder perusahaan

2. Data primer \& sekunder diolah dan dihitung biaya

3. Data yang telah dihitung dianalisis dengan menggunakan metode EOQ dan JIT.

4. Setelah dianalisis lalu diambil kesimpulan dan saran

A. Metode EOQ

$E O Q=Q^{*}=\sqrt{\frac{2 x R x S}{C}}$

(Sumber: Maharani, 2015)

Keterangan :

$Q^{*} \quad=$ Economic Order Quantity (EOQ)

$\mathrm{S} \quad=$ Biaya Pesanan per pemesanan

$\mathrm{R}=$ Total penggunaan bahan baku per periode

$\mathrm{C} \quad=$ Biaya penyipanan per unit 
Q $\quad=$ Kuantitas pemesanan (Unit Order)

B. Reorder Point

$$
R O P=S S+(L T \times A U)
$$

(Sumber: Sari , 2010)

ROP = titik yang menunjukkan tingkat persediaan sehingga perusahaan harus memesan kembali $(\mathrm{kg})$

LT = tenggang waktu antara pemesanan sampai kedatangannya di gudang (hari)

$\mathrm{AU}=$ pemakaian rata-rata dalam satu satuan waktu tertentu ( $\mathrm{kg} / \mathrm{hari})$

SS = safety stock $(\mathrm{kg})$

C. Safety Stock

$\mathrm{SS}=Z \times S L$

(Sumber: Sari , 2010)

Keterangan:

$\mathrm{SS}=$ Persediaan pengaman $(\mathrm{kg})$

$Z=$ Nilai $\alpha$ dengan penyimpangan sebesar $5 \%$ yang dilihat pada tabel Z

(kurva normal).

$\mathrm{SL}=$ Standar Deviasi kebutuhan bahan baku gula periode produksi 2016/2017 - 2018/2019

D. Just In Time menentukan jumlah pengiriman optimal

$Q n=\sqrt{n \times Q^{*}}$

(Sumber: Maharani, 2015)

Keterangan :

$Q n=$ Kuantitas Pemesanan JIT

$n$ = Frekuensi Pengiriman

$Q^{*} \quad=$ Kebutuhan Bahan Baku Per Periode

E. JIT menentukan Jumlah unit Optimal

$q=\frac{Q^{8}}{n}$

(Sumber: Maharani, 2015)

Keterangan :

$q$ = Jumlah unit optimal

$n=$ Frekuensi Pengiriman

$Q^{*}=$ Kebutuhan Bahan Baku Per Periode

F. menghitung biaya JIT

$$
\text { Tjit }=\frac{1}{\sqrt{n}}\left(T^{*}\right)
$$

(Sumber: Maharani, 2015)

Keterangan :

Tjit = Biaya Total JIT

$n=$ Frekuensi Pengiriman

$T^{*} \quad=$ Biaya Pemesanan

\section{ANALISIS DAN PEMBAHASAN DATA}

Analisis data bahan baku gula pada PT.

Singa Mas Indonesia pada tiga tahun periode produksi minuman kemasan, data berikut meliputi data penggunaan gula setiap bulan/tahun, kuantitas pemesanan per pemesanan, frekuensi pemesanan serta total biaya persediaan bahan baku gula periode produksi 2016/2017-2018/2019.

Tabel 1. Total Penggunaan Bahan Baku Gula

\begin{tabular}{|c|c|c|c|}
\hline \multirow{2}{*}{ Bulan } & \multicolumn{3}{|c|}{ Penggunaan Bahan Baku (Kg) } \\
\hline & $2016 / 2017$ & $2017 / 2018$ & 2018/2019 \\
\hline Juli & 30000 & 24000 & 32000 \\
\hline Agustus & 24000 & 30000 & 34000 \\
\hline September & 28000 & 26000 & 32000 \\
\hline Oktober & 24000 & 22000 & 24000 \\
\hline November & 40000 & 28000 & 28000 \\
\hline Desember & 26000 & 42000 & 26000 \\
\hline Januari & 38000 & 46000 & 30000 \\
\hline Februari & 24000 & 24000 & 30000 \\
\hline Maret & 48000 & 32000 & 54000 \\
\hline April & 24000 & 30000 & 28000 \\
\hline Mei & 42000 & 44000 & 38000 \\
\hline Juni & 26000 & 28000 & 26000 \\
\hline Jumlah & 374000 & 376000 & 382000 \\
\hline Rata-Rata & 27000 & 29000 & 30000 \\
\hline
\end{tabular}
Periode Tahun 2016-2018.

Sumber: PT. Singa Mas Indonesia

Untuk dapat menjalankan kegiatan produksi, pabrik harus mengetahui jumlah penggunaan gula. Berdasarkan tabel 4.1 penggunaan gula tertinggi adalah pada periode produksi 2018/2019 dengan jumlah $382.000 \mathrm{Kg}$, dengan penggunaan rata-rata perbulan $30.000 \mathrm{~kg}$, sedangkan penggunaan gula terendah adalah pada periode produksi 2016/2017 dengan jumlah $374.000 \mathrm{Kg}$ dengan penggunaan ratarata per bulan $27.000 \mathrm{~kg}$.

Tabel 2. Kuantitas dan frekuensi Pemesanan Bahan Baku Gula di PT. Singa Mas Indonesia Periode 20016/2017 - 2018/2019.

\begin{tabular}{|c|c|c|c|}
\hline Periode & $\begin{array}{c}\text { Kuantitas } \\
\text { Pemesanan per } \\
\text { Pemesanan (kg) }\end{array}$ & $\begin{array}{c}\text { Frekuensi } \\
\text { (kali) }\end{array}$ & $\begin{array}{c}\text { Total } \\
\text { Penggunaan } \\
\text { Gula (kg) }\end{array}$ \\
\hline $2016 / 2017$ & 18.700 & 20 & 374.000 \\
\hline $2017 / 2018$ & 16.348 & 23 & 376.000 \\
\hline $2018 / 2019$ & 15.280 & 25 & 382.000 \\
\hline
\end{tabular}

Sumber: PT. Singa Mas Indonesia

Berdasarkan Tabel 4.2 dapat diketahui bahwa kuantitas pemesanan per pemesanan paling tinggi terjadi pada periode produksi 2016/2017 sebesar $18.700 \mathrm{~kg}$ jumlah tersebut adalah kemampuan perusahaan untuk melakukan pemesanan bahan baku, dengan jumlah pemesanan per pesanan tersebut frekuensi pemesanan yang harus dilakukan sebesar 20 kali, sedangkan untuk 
penggunaan bahan baku gula yang dibutuhkan dalam setahun yaitu sebesar $374.000 \mathrm{Kg}$.

Tabel 3. Total Biaya Persediaan Bahan Baku Gula Periode Produksi 2016/2017-2018/2019.

\begin{tabular}{|c|c|c|c|}
\hline Periode & $\begin{array}{c}\text { Biaya } \\
\text { Pemesanan }\end{array}$ & $\begin{array}{c}\text { Biaya } \\
\text { Penyimpanan }\end{array}$ & $\begin{array}{l}\text { Tota Biaya } \\
\text { Persediaan }\end{array}$ \\
\hline $2016 / 2017$ & Rp22.000.000 & Rp62.000.000 & Rp84.000.000 \\
\hline $2017 / 2018$ & Rp26.000.000 & Rp66.000.000 & Rp92.000.000 \\
\hline $2018 / 2019$ & Rp28.000.000 & Rp68.000.000 & Rp96.000.000 \\
\hline
\end{tabular}

Sumber: PT. Singa Mas Indonesia

biaya pemesanan periode produksi 2016/2017 diketahui sebesar Rp. 22.000.000 jumlah tersebut adalah biaya yang dibutuhkan untuk melakukan pemesanan bahan baku sebanyak 20 kali pemesanan dalam satu tahun, sedangkan biaya penyimpanan periode produksi 2016/2017 sebesar Rp. 62.000.000, Sehingga total biaya persediaan periode produksi 2016/2017 didapatkan sebesar Rp. 84.000.000.

\section{HASIL}

Tabel 4. Analisis Kuantitas Pemesanan Frekuensi Pembelian dan Total Biaya Persediaan Bahan Baku Gula Antara Kebijakan Perusahaan, Dengan Metode Economic Order Quantity dan Just In Time Periode 2016/2017.

\begin{tabular}{|c|c|c|c|}
\hline No & Indikator & $\begin{array}{c}\text { Kebijakan } \\
\text { Perusahaan }\end{array}$ & EOQ \\
\hline 1 & $\begin{array}{c}\text { Kebutuhan } \\
\text { Bahan Baku } \\
(\text { Kg) }\end{array}$ & 374.000 & 374.000 \\
\hline 2 & $\begin{array}{c}\text { Frekuensi } \\
\text { Pengiriman }\end{array}$ & 20 & 5 \\
\hline 3 & $\begin{array}{c}\text { Kuantitas } \\
\text { Pemesanan (Kg) }\end{array}$ & 18.700 & 70.451 \\
\hline 4 & $\begin{array}{c}\text { Total Biaya } \\
\text { Persediaan (Rp) }\end{array}$ & 84.000 .000 & 11.679 .041 \\
\hline
\end{tabular}

(Tabel Lanjutan ...)

\begin{tabular}{|c|c|c|c|}
\hline \multicolumn{5}{|c|}{ JIT } \\
\hline Lot Pemesanan & $\begin{array}{c}\text { Kapasitas } \\
\text { Minimum }\end{array}$ & $\begin{array}{c}\text { Tingkat } \\
\text { Persediaan } \\
\text { Rata-rata }\end{array}$ & $\begin{array}{c}\text { Prosentase } \\
\text { Penghematan } \\
\text { Biaya }\end{array}$ \\
\hline 374.000 & 374.000 & 374.000 & 374.000 \\
\hline 96 & 37 & 177 & 100 \\
\hline 3.896 & 10.000 & 2.117 & 3.740 \\
\hline 2.244 .898 & 3.618 .421 & 1.692 .308 & 2.200 .000 \\
\hline
\end{tabular}

Berdasarkan Tabel 4.18 dapat dianalisa perbandingan efisiensi kuantitas pembelian bahan baku dan frekuensi pemesanan gula kebijakan perusahaan pada periode produksi 2016/2017 yaitu $18.700,00 \mathrm{Kg}$ dengan frekuensi pemesanan sebanyak
20 kali, sehingga didapatkan total biaya persediaan sebesar Rp 84.000.000. sedangkan untuk metode EOQ didapatkan frekuensi pengiriman sebanyak 5 kali, dengan kuantitas per pengiriman sebesar $70.451 \mathrm{Kg}$, sehingga total biaya persediaan yang harus dikeluarkan adalah sebesar $\mathrm{Rp}$ 11.679.041. Untuk metode just in time berdasarkan lot pemesanan menurut peneliti adalah jumlah pengiriman optimal yaitu 96 kali dalam satu tahun, maka dalam satu bulan terdapat 8 kali pengiriman, sedangkan jumlah kuantitas pemesanan sebesar $3.896 \mathrm{Kg}$ per pengiriman, sehingga didapatkan total biaya JIT sebesar Rp 2.244.898.

\section{KESIMPULAN}

1. Pengendalian persediaan bahan baku gula kebijakan perusahaan periode 2016/2017 kuantitas sebesar $18.700 \mathrm{Kg}$, frekuensi 20 kali, total biaya persediaan sebesar Rp 84.000.000. Analisis EOQ periode produksi 2016/2017 kuantitas sebesar $70.451 \mathrm{Kg}$, frekuensi 5 kali, total biaya persediaan sebesar Rp. 11.679.041. Waktu tunggu kedatangan bahan baku gula yang optimal menurut metode EOQ periode produksi 2016/2017-2018/2019 adalah selama 3 hari. Safety stock menurut metode EOQ sebesar $13.111 \mathrm{Kg}$, dan titik pemesanan kembali periode produksi 2016/2017-2018/2019 saat persediaan digudang tinggal 16.286; 16.457; $16.687 \mathrm{Kg}$. Pada metode JIT, perusahaan melakukan pemesanan bahan baku tanpa disimpan pada gudang penyimpanan dengan tujuan bahan baku langsung diproduksi. Berdasarkan perhtitugan metode JIT periode produksi 2016/2017 lot kuantitas pemesanan sebesar $3.896 \mathrm{Kg}$, frekuensi pengiriman 96 kali, total biaya JIT Rp. 2.244.898.

2. Proyeksi pengendalian persediaan bahan baku gula tahun 2019/2020 metode EOQ kuantitas sebesar $68.191 \mathrm{~kg}$, frekuensi $6 \mathrm{kali}$, total biaya persediaan Rp. 13.005.493, sedangkan proyeksi metode JIT kuantitas sebesar $4.042 \mathrm{~kg}$, frekuensi seesar 96 kali, total biaya JIT Rp. 2.461.538.

\section{SARAN}

Dalam pengendalian persediaan bahan baku gula, PT. Singa Mas Indonesia sebaiknya melakukan pemaksimalan kapasitas gudang penyimpanan bahan baku gula sehingga pembelian gula dapat dilakukan dengan jumlah kuantitas pemesanan dengan jumlah yang lebih besar (optimal) dengan frekuensi pemesanan yang rendah per periode produksi, hal ini untuk meminimalisir biaya total persediaan yang diantaranya yaitu biaya pemesanan dan biaya penyimpanan. 


\section{DAFTAR PUSTAKA}

Ahyadi Harwan, Khodijah Siti, 2017. "Analisis Pengendalian Persediaan Suku Cadang Pesawat B737-Ng Dengan Pendekatan Model Periodic Review Di Pt. X”, Bina Teknika Jurnal, Volume 13, Nomor 1, Edisi Juni 2017, Halaman 47-58.

Handoko Hani, M.B.A, 1990 “Dasar-Dasar Manajemen Produksi Dan Operasi", cetakan ke-3 Januari, Penerbit BPFEYOGYAKARTA.

Maharani M Hayundra dan Kamal Mustofa, 2015. "Perbandingan Sistem Economic Order Quantity Dan Just In Time Pada Pengendalian Persediaan Bahan Baku”, Diponegoro Journal Of Management, Volume 4, Nomor 2, Tahun 2015 ISSN (Online): 2337-3792, Halaman 1-15.

Nugraha Aditya, 2015 , "Analisis Pengendalian Bahan Baku Menggunakan Metode Eqonomic Order Quantity (Eoq)(Studi Kasus Pada Family Citra Bakery)", Jurusan Manajemen Fakultas Ekonmi Universutas Negeri Semarang, Skripsi hal 1-83.

Nuryanto Aris, 2010 ."Analisis Perbandingan Pengendalian Persediaan Bahan Baku Kain Micropolar Fleece Antara Pendekatan Model Eoq Dengan Just In Time Inventory Control (Jit/Eoq) Pada Cv Cahyo Nugroho Jati Sukoharjo", Fakultas Ekonomi Universitas Sebelas Maret Surakarta, Tugas Akhir hal 1124.

Sari Septi Pandan, 2010. "Pengoptimalan Persediaan Bahan Baku Kacang Tanah Menggunakan Metode Eoq (Economic Order Quantity) Di Pt. Dua Kelinci Pati" Universitas Sebelas Maret, Februari, Skripsi Hal-1-108.

Soebandi Koesmawan A., M.Se \& Dr. Sobarsa Kosasih, ME, 2014. "MANAJEMEN OPERASI" , cetakan ke-2, Penerbit Mitra Wacana Media, ISBN 978-602-1353-02-8.

Simanjuntak Desy Juliana dan Sidharta Juaniva, 2017. "Perbandingan System Economic Order Quantity Dan Sistem Just In Time Terhadap Efisiensi Biaya Bahan Baku Pada PT. Tricitra Agri Perdana", Fundamental Management Journal Online, eISSN: 25409220 Volume: 2 online No.1.
Syukron Amin, Muhammad Kholil, 2014. "Pengantar Teknik Industri", cetakan ke-1, Penerbit Graha Ilmu, ISBN 978-602-262-1935.

Tampubolon Manahan, 2004. "Manajemen Operasional”, cetakan ke-1, Penerbit Ghalia Indonesia, ISBN 979-450-476-9.

Turnip Melpa Syari Kristiani, Kartikasari Dewi, 2017. "Analisis Perbandingan Pengendalian Persediaan Bahan Baku Methanol Antara Pendekatan Model Economic Order Quantity Dengan Just In Time Pada Cv Mamabros Servicindo Batam", Journal of Applied Managerial Accounting e-ISSN 2548-9917 (JAMA), Vol 1, No 2 , hlm 1-15. 